University of Wollongong

Research Online

Faculty of Engineering and Information

Faculty of Engineering and Information

Sciences - Papers: Part A

Sciences

$1-1-2013$

\title{
Unintended adverse consequences of introducing electronic health records in residential aged care homes
}

Ping Yu

University of Wollongong, ping@uow.edu.au

Yiting Zhang

University of Wollongong, yz709@uowmail.edu.au

Yang Gong

University of Texas Health Science Center at Houston

Jianjia Zhang

University of Texas Health Science Center at Houston, jz163@uowmail.edu.au

Follow this and additional works at: https://ro.uow.edu.au/eispapers

Part of the Engineering Commons, and the Science and Technology Studies Commons

Research Online is the open access institutional repository for the University of Wollongong. For further information contact the UOW Library: research-pubs@uow.edu.au 


\title{
Unintended adverse consequences of introducing electronic health records in residential aged care homes
}

\begin{abstract}
The aim of this study was to investigate the unintended adverse consequences ofintroducing electronic health records (EHR) in residential aged care homes (RACHs) and toexamine the causes of these unintended adverse consequences. Method: A qualitative interview study was conducted in nine RACHs belonging to three orga-nisations in the Australian Capital Territory (ACT), New South Wales (NSW) and Queensland,Australia. A longitudinal investigation after the implementation of the aged care EHR systems was conducted at two data points: January 2009 to December 2009 and December 2010to February 2011. Semi-structured interviews were conducted with 110 care staff membersidentified through convenience sampling, representing all levels of care staff who workedin these facilities. Data analysis was guided by DeLone and McLean Information SystemsSuccess Model, in reference with the previous studies of unintended consequences for theintroduction of computerised provider order entry systems in hospitals.Results: Eight categories of unintended adverse consequences emerged from 266 data itemsmentioned by the interviewees. In descending order of the number and percentage of staffmentioning them, they are: inability/difficulty in data entry and information retrieval, enduser resistance to using the system, increased complexity of information management, enduser concerns about access, increased documentation burden, the reduction of communi-cation, lack of space to place enough computers in the work place and increasing difficultiesin delivering care services. The unintended consequences were caused by the initial condi-tions, the nature of the EHR system and the way the system was implemented and used bynursing staff members.Conclusions: Although the benefits of the EHR systems were obvious, as found by our previ-ous study, introducing EHR systems in RACH can also cause adverse consequences of EHRavoidance, difficulty in access, increased complexity in information management, increaseddocumentation burden, reduction of communication and the risks of lacking care follow-up, which may cause negative effects on aged care services. Further research can focus oninvestigating how the unintended adverse consequences can be mitigated or eliminated byunderstanding more about nursing staff's work as well as the information flow in RACH.This will help to improve the design, introduction and management of EHR systems in this setting.

\author{
Disciplines
}

Engineering | Science and Technology Studies

\section{Publication Details}

Yu, P., Zhang, Y., Gong, Y. \& Zhang, J. (2013). Unintended adverse consequences of introducing electronic health records in residential aged care homes. International Journal of Medical Informatics, 82 (9), 772-788.
\end{abstract}




\section{Title page}

Title of the manuscript: Unintended adverse consequences of introducing electronic health records in residential aged care homes

Authors of the manuscript: Ping $\mathrm{Yu}^{\mathrm{a}}$, Yiting Zhang ${ }^{\mathrm{a}}$, Yang Gong ${ }^{\mathrm{b}}$, Jiajie Zhang ${ }^{\mathrm{b}}$

Affiliation of the authors: ${ }^{\mathrm{a}}$ School of Information Systems and Technology, University of Wollongong, Wollongong, 2522, NSW, Australia

${ }^{\mathrm{b}}$ School of Biomedical Informatics, University of Texas Health Science Center at Houston, 7000, Fannin Street, Suite 600, Houston, Texas 77225, USA

Corresponding author: Ping Yu, PhD, University of Wollongong, Wollongong 2522, NSW, Australia, Tel.: +61242215412, Fax: +61242214045, E-mail: ping@uow.edu.au

Citation: Yu P, Zhang YT, Gong Y, Zhang JJ. (2013) Unintended adverse consequences of introducing electronic health records in residential aged care homes. International Journal of Medical Informatics. http://dx.doi.org/10.1016/j.jimedinf.2013.05.008 


\section{ABSTRACT}

Purpose: The aim of this study was to investigate the unintended adverse consequences of introducing electronic health records (EHR) in residential aged care homes (RACH) and to examine the causes of these unintended adverse consequences.

Method: A qualitative interview study was conducted in nine RACHs belonging to three organisations in the Australian Capital Territory (ACT), New South Wales (NSW) and Queensland, Australia. A longitudinal investigation after the implementation of the aged care EHR systems was conducted at two data points: January 2009 to December 2009 and December 2010 to February 2011. Semi-structured interviews were conducted with 110 care staff members identified through convenience sampling, representing all levels of care staff who worked in these facilities. Data analysis was guided by DeLone and McLean Information Systems Success Model, in reference with the previous studies of unintended consequences for the introduction of computerised provider order entry systems in hospitals.

Results: Eight categories of unintended adverse consequences emerged from 266 data items mentioned by the interviewees. In descending order of the number and percentage of staff mentioning them, they are: inability/difficulty in data entry and information retrieval, end user resistance to using the system, increased complexity of information management, end user concerns about access, increased documentation burden, the reduction of communication, lack of space to place enough computers in the work place and increasing difficulties in delivering care services. The unintended consequences were caused by the initial conditions, the nature of the EHR system and the way the system was implemented and used by nursing staff members.

Conclusions: Although the benefits of the EHR systems were obvious, as found by our previous study, introducing EHR systems in RACH can also cause adverse consequences of EHR avoidance, difficulty in access, increased complexity in information management, increased documentation burden, reduction of communication and the risks of lacking care follow-up, which may cause negative effects on aged care services. Further research can focus on investigating how the unintended adverse consequences can be mitigated or eliminated by understanding more about nursing staff's work as well as the information flow in RACH. This will help to improve the design, introduction and management of EHR systems in this setting. 
Key words: Unintended adverse consequences, Implementation, Electronic health records, Nursing documentation, Interview, Long term care, Nursing home, Residential aged care, Sociotechnical approach 


\section{Introduction}

Health record management is a fundamental component of nursing and one of the most important tasks nursing staff in residential aged care homes (RACHs) undertake [1, 2]. It is also the task that nursing staff is often frustrated with. It is a well-documented fact that paper records cannot effectively support modern care services because of the inefficiency and difficulties of accessing, entering and retrieving data that may be inaccurate, illegible, incomplete or out-of-date. In addition, the recording tasks take nursing staff away from their core duty of providing direct care to the elderly [2-8]. In order to meet the needs of person-centred care, improve record management, comply with health regulations, support efficient information exchange between health care providers for multidisciplinary collaboration through the continuum of care, electronic health records (EHR) are being increasingly introduced in RACHs in Australia to replace paper-based records $[1,5,9,10]$.

The expectation is that EHR systems in RACHs will replace paper records and overcome the aforementioned deficiencies. Our longitudinal, multiple case study in nine RACHs in three states/territories in Australia has identified the following benefits of the EHR systems [11]: legibility; ease of access; quick data entry and retrieval; convenience in data storage and distribution; improvement in the quality of individual residents' health records; better information management in the organisation; information and knowledge growth as well as empowering the staff; better communication between the residents and aged care staff, among the staff members and with external health care providers; an increase in the management's ability to monitor and control the care delivery and quality; an improvement in the working environment and educational benefits.

Despite successes and benefits, by and large EHR adoption has been slow internationally [12-14]. The effects and functions of IT applications in work practices are not pre-determined, but evolve within the specific sociotechnical contexts of these practices. To ensure the introduced system and practice meet the expectations, any weaknesses or risks associated with the introduction of EHR, any unintended adverse consequences (UACs) on the elderly, the nursing staff and the organisations need to be identified, categorised and documented [5, 15]. This in-depth understanding can help decision makers better design strategies and approaches for the deployment of the systems which will avoid mistakes and achieve the optimal outcomes [16]. 
Unintended consequences (UC) are those consequences, either fortunate or unfortunate, which are neither anticipated nor planned for but come about due to the introduction of EHRs [17]. Unintended adverse consequences (UACs) [18] can become impediments to the quality of record management and care [19]. Careful identification, description and categorisation of UCs can help stakeholders predict, monitor and manage them [19]. With a good understanding of UCs, it is hoped that EHR systems can be designed, implemented and used effectively to avoid undesired outcomes in complex health care environments [17, 20, 21].

Several studies have identified the UCs of computerised provider order entry (CPOE) systems in hospitals and clinical centres in the United States [17-20, 22, 23]. Ash et al. categorised these UCs into desirable or undesirable and direct or indirect ones, drawing on the literature [14]. These include: increased documentation burden (including inefficiency of entering and retrieving information); unfavourable workflow; never-ending system demands; the continued use of paper documents ; difficulty and reduction of multidisciplinary communication among care providers; difficulty to adopt the system or even rejection of its use; information and medication administration errors; unexpected changes in the power structure and overdependence on the technology $[17,20]$.

A study which interviewed 83 clinicians, suggested that stakeholders were usually unaware of the UCs of the systems [23]; however a nation-wide telephone survey at 561hospitals and interviews at 176 hospitals led to the suggestion that UCs were prevalent whenever CPOE systems were introduced in hospitals [19]. In an expert group discussion of the above results, it is recommended that continuous management of UCs is needed to ensure system success [22].

Koppel et al. [24] also report that a leading CPOE system in a tertiary hospital in the United States frequently caused medication errors. By analysing and synthesising the results of previous research [17, 20], Harrison et al. [21] have developed a conceptual model of 5 'interactive sociotechnical analysis types' to draw the attention of practitioners to UCs during health information technology implementation. These include: new IT changes the existing social system, technical and physical infrastructures mediate health information 
technology (HIT) use, social system mediates HIT use, HIT-in-use changes the social system, HIT-social system interactions engender HIT redesign [21].

In addition to CPOE systems, the UCs of other HIT systems, such as electronic medication management systems, have been studied. One study has focused on an electronic medication administration record system in 5 nursing homes [25] and another on a barcode medication administration system in 5 hospitals [26]. Two studies find that the systems lead to workarounds of both nursing home staff and nurses and physicians in hospitals because the information flow in the system does not match real workflow. This may have critical implications for patient safety as it may increase medication error [25, 26]. In addition, it has been found that an electronic medical record system which is isolated from the rest of the IS in a local facility can reduce clinicians’ productivity [27].

There are also studies identifying undesired consequences of EHR systems in hospitals and private practice settings. Linder et al. [28] found that despite the high cost of introducing it, an EHR system used in a hospital in the United States brought neither an obvious return on investment, nor an improvement in the quality of daily ambulatory care. Cresswell et al. [29] report that hospital nurses had to spend more time running paper and electronic records in parallel because of the limited functionality of the EHR system. Previous studies have also shown general practitioners' (GPs') anxiety and fear of using EHRs in private practice in Austria, caused by concerns about data accuracy, privacy and security as well as the change of workflow, without experiencing any obvious benefits [30].

There are a few previous studies in residential [15, 31, 32] and community [33] aged care settings suggesting that EHR systems reduced record accessibility, decreased the efficiency of documentation and led to poor quality and incomplete records and an increased error rate. To date, little is known about the unintended consequences of EHR systems in RACHs despite the vital importance of this knowledge for EHR success. Berg suggests that the potential roles of IT applications in health care are best understood by a socio-technical qualitative research approach [34] to gather empirical knowledge, using methods such as participant observation and interviews. We have reported the findings of our qualitative interview study on the benefits of EHR systems [1] and observational study into the impact of the systems on care staff's work [35, 36]. 
Therefore, the aim of this paper is to report the UAC of these systems and their causes as perceived by care staff members at all levels of the participant aged care organisations.

\section{Methods}

\subsection{The study sites}

Nine RACHs belonging to 3 organisations -- RSL Care, Uniting Care Ageing South Eastern Region and Warrigal Care -- participated in the study through a formal research partnership with the University of Wollongong. The RACHs, located in the Australian Capital Territory (ACT), New South Wales (NSW) and Queensland, provided either high, or both high and low levels of care services. The size of the RACHs ranged from 60 to 152 beds. Six RACHs were located in urban areas, 2 were in regional areas and one in a rural region.

\subsection{Theoretical framework}

DeLone and McLean's Information Systems Success Model (D\&M IS Success Model) [37] has been adopted as the theoretical framework in this study in order to measure the UCs of the EHR systems in RACHs. The components of the original model include system quality, information quality, use, user satisfaction, individual impact and organisational impact [38]. The updated model provides a comprehensive taxonomy of IS success variables: system quality, information quality, service quality, use, user satisfaction and net benefits [37]. According to Delone and McLean [37], system quality measures the characteristics of an IS in terms of adaptability, availability, reliability, response time and usability. Information quality captures the content of an IS. The common metrics for measuring it are completeness, ease of understanding, personalisation, relevance and security. Service quality is the overall support delivered by the service provider. The service may be provided by the IS department, the outside system vendor or a third party service provider such as an internet service provider (ISP). It is measured by assurance, empathy and responsiveness. Use or usage measures everything from a visit to an IS, to navigation within the IS, to information retrieval or execution of a transaction. User satisfaction refers to system users' opinions of the IS. It should cover the entire experience from log-in to log-out. Net benefits are the most important IS success measures. They are the balance of positive and negative impacts of the IS. Net benefit measures are determined by the context and 
objective of each IS and cannot be individually analysed and understood without knowing the context and objectives of the introduction of the system.

This model provides the causal relationships of the various factors that determine the output for the introduction of an IS [39]. It also provides adequate reference points from the perspective of technical success, semantic success and effectiveness. Technical success is measured by 'system quality'. Semantic success is measured by 'information quality'. Effectiveness is manifested by 'use, user satisfaction, individual impacts and organisational impacts' [37]. As DeLone and McLean [37] note, the variables in the model will be positive or negative according to the context - the system and the interaction between the system and its end-users. The broad scope of this model provides a solid framework for categorising the consequences of introducing IS into organisations as well as the causes for the consequences.

\subsection{The EHR systems implemented}

Two commercial aged care EHR systems (System X and Y) from two different companies were used by the RACHs. System X was used in a regional RACH. System Y was used in 6 urban, 1 regional and 1 rural RACH . The EHR systems contained demographics, assessments, care plans, progress notes, vital signs, past medical history and current medical diagnosis. One system (System Y) had a shift hand-over module and a module for the calculation of funding levels according to the Australian government aged care funding instrument (ACFI) - an important part of health records in RACHs, which was used to appraise a resident's dependency or need for care by the Australian Government in determining the level of funding to RACHs. The EHR systems also provided the function for end users to build forms.

\subsection{Participants and data collection}

Ethics approval was granted by the institutional ethics committee. The date and time of access to RACHs was agreed upon between the second author (PY) who conducted the interviews and the management of the relevant organisation. Interview questions were framed according to the D\&M IS Success Model and were designed to elicit nursing staff's perceptions of the implementation processes and outcomes of the EHR. The instrument validation process is described in [11]. 
110 nursing staff members participated in interviews over two time periods: January 2009 to December 2009 and December 2010 to February 2011. PY conducted the interviews. On each visit to a site, she first asked the management about staffing arrangement, then recruited participants through convenience sampling. At each site, the staff members in all job roles were interviewed. The interview was concluded when no further issues emerged, i.e., at the point of saturation. End users of the EHR system in all types of positions were selected to fully understand the perceptions of the different levels of users. The informants included 45 personal care workers (PCWs), 6 endorsed enrolled nurses (EENs) or enrolled nurses (ENs), 15 registered nurses (RNs), 31 managers and 13 other staff. The data captured included the type of aged care home (high care or low care), the staff member's gender, the years s/he had worked in the RACH, his/her previous computer literacy level and training experience with the EHR system, as well as the care staff member's perceptions about strength, weakness, opportunities and any perceived threat brought about by the introduction of the EHR system. To avoid embarrassment, their age was not explicitly asked but guessed by the interviewee. The semi-structured interviews were audio-recorded and transcribed by professional transcribers into Microsoft Word documents. The total recording time is approximately 32 hours, with 428 pages of A4 size transcripts generated.

\subsection{Data analysis}

The collected transcripts were analysed by the first two authors using the content analysis method in Microsoft Excel. To enhance trustworthiness, data were analysed by the three authors who had not been directly involved in the field data collection. The detailed content analysis methods are described in our published study of the benefits of the EHRs [11]. All the quotations from the transcripts that were related to UACs and their causes were selected, copied to and analysed in an Excel spreadsheet. Various functions of Excel including highlighting cells, data sorting, filtering, cell counting and the PivotChart were used together to undertake a grounded theory approach of constant comparison [40]. The quotations were counted and merged into categories. The category system of UACs was continuously refined based on the category framework of our previous study. Final agreement on the category system between the authors was reached after three months of constant comparison and discussion. 266 UACs were identified from the transcripts. Comparison and classification led to 8 categories of UACs. According to the typology that Campbell et al. [17] established, this number is considered ideal because it is small enough to be manageable, yet broad enough 
for the researchers to examine the large number of issues revealed in the data set. Any difference in classification was resolved in discussions among research team members until full agreement was reached.

\section{Results}

Despite one PCW declined to be interviewed, stating the reason to be that she was in the process of leaving the organisation and it was not neutral for her to comment on the system in her organisation, all the informants the interviewer approached gave the consent and participated in the interview. In total, 85 (78\% ) interviewees mentioned certain type of UAC. This includes 11 (35\%) managers, 7 (47\%) RNs, 2 (33\%) EENs, 10 (22\%) PCWs and 4 (31\%) other staff. The impression of the interviewer was that about 70 (64\% ) interviewees were in the age group of between 40 and 55, 25 (23\%) were in their 30s, 8 (7\%) were in the age group of between 55 and 65, and 6 (5\% of) interviewees were in their 20s. In accordance with the demographic profile of aged care workers in Australia [41], 102 (93\% ) interviewees were female staff members.

Eight categories of UAC emerged from the 266 recordings. In descending order of number and percentage of staff mentioning them, they are: inadequate functionality and poor interface design of the EHR system, resistance to using the system, increased complexity of information management, concerns about access, increased documentation burden, a reduction in communication, lack of space to place enough computers in the work place and increasing difficulties in delivering care services (Table 1). The key findings about the staff members' perceptions of these UACs are presented in the following sections.

Insert Table 1 here.

\subsection{Inability/difficulty to input data and retrieve information}

40 nursing staff members (43\%) suggested 75 times that the inadequate functionality and poor user-interface design caused inability/difficulty to input data and retrieve information for the provision of care services that were supposed to be supported by the system. The main functions which were considered inadequate included a lack of certain types of electronic forms, inefficient support for the development of care plans, the inability to quickly find the relevant information in certain sections of forms or charts, poor interoperability with other IS systems used by other health service providers, difficulty in generating reports and predicting trends, and a 
lack of a built-in spell-check function. Staff members' reports about inadequate user-interface are discussed next.

Four nursing staff members at different levels raised problems with filling in the forms. The options in the assessment were too 'black and white' to represent a true picture of a resident. Many options in drop-down lists were inappropriate in the pain and wound chart. And free text was not allowed to be inputted in this kind of field, which the care staff thought would have been useful.

For example with wound care it simply says what colour is the wound - red, yellow or black. That was all the information you could provide...you often can't put your own information in. Manager 324

Suggestions about redesign of the forms were heard in the interviews. One PCW reported that the place where they needed to enter the information was 'odd', while another manager thought the forms were too long, and could be simplified. Another manager pointed out that after a system update she could no longer see at a glance who had wounds, so they stopped using the charts in the system.

For example the sacrum... that's one of the biggest wounds and we can't even click on it. We go back to the C11. - Manager 371

\section{A lack of certain types of electronic forms}

23 entries from 16 nursing staff members (15\%) reported the problem of an inadequate number of electronic forms in the EHR system. More than half of them came from Organisation 1 because handover functions and the assessment forms for the Australian government Aged Care Funding Instrument (ACFI) were not built into System X even though nursing staff members felt strongly that these two functions were needed. A variety of other additional missing forms were suggested. These included fall risk assessments, medication management charts, an electronic version of the maintenance book, restraint charts, urinary output charts, pain assessments, particular forms such as initial physiotherapy assessments for allied health professionals (AHPs), leisure interests for diversional therapists, letters and lifestyle assessments for recreational activities officers. It was recommended that the forms and functions in the EHR system should be continuously updated to remain relevant to the needs of recording daily care routines and outcomes. 
So unless there can be a handover, using [System X], I don't think it would improve things straight away. - RN 256

A few charts we do, that would be to say the restraint charts, the urinary output chart, pain assessment chart that we use. The output chart on [System Y] would be awesome. - PCW 453

\section{Inefficient support for care plan development}

Seven nursing staff members (6\%) suggested that the procedure for the development of the electronic care plan was inefficient. One RN wished to switch care plans among residents and copy useful information from one to another who needed similar care services. A PCW and a manager wanted to see the relevant information that had already been entered into progress notes in the EHR system be automatically populated into the care plan page. It was suggested that resuscitation and safety issues be included in the electronic care plan. In a physio assistant's opinion, the electronic care plans could be shortened and made more concise, so that RNs and nursing managers could evaluate them more quickly and easily.

I would like the progress notes to go into the care plans because a lot of the behaviours are captured in the progress notes. So for instance if a pain chart hasn't been done it is not captured in the care plans. - PCW 276

I would like the system to automatically generate a care plan based on what is already entered into the system about one person because all the information is there but we then still have to put together the care plan. That would be fantastic, and it would save so much time. - Manager 305

Another manager reported that the system did not change the review date of a care plan when she evaluated it. The only way of updating a care plan was to create a new one; however it was difficult and time-consuming to do that because when she wanted to refer to the original care plan, she had to go through the archives. The manager expressed the view that it was easier to review and update a care plan on paper.

...on the paper-based you would have your list of evaluations, and you can see where it has been crossed out, and the number of times a person has been to a specialist has been recorded and when they had been to a dentist. It was easy to determine when they needed to go to the dentist next. - Manager 325

\section{Inability to quickly find the relevant information at certain sections of forms or charts}

One RN expressed her frustration with the layout and design of the forms slowing her down: 
[When] moving between say each bowel chart, you have to go a long way round instead of having a quick link in between. - PCW 588

Eight nursing staff members (7\%) expressed their need to move quickly from the current view to other information they needed to see, for example: moving to another resident's information within the same type of form/chart, jumping to another section within the same form by either keyword search or searching the title of the section or scrolling backward to the previously entered information on the same type of form/chart for the same people by simply clicking a button on the screen.

\section{Poor interoperability with the IS systems used by other health service providers}

Three managers and one customer service officer mentioned their concern with the poor interoperability of the EHR system with other IS systems used in the organisation. They suggested that outside health care providers, especially GPs, would like to access the aged care EHR system as it would be easier for the GPs to input data into their own system and let nursing staff members in an RACH access the information in the aged care EHR system.

Another manager wanted to access the system when she accompanied a resident to hospital and wrote the progress notes the same day, however she could only enter the notes into the computer when she came back to the aged care home. Establishing interoperability between the aged care EHR system and the IS in a hospital or a GP's office would solve the problem.

As technology expands I think [the EHR system] should hopefully expand and I guess link in with other allied health and doctors and things like that. - Manager 279

The doctors we are having a lot of problems with them. They are very reluctant to use them because they believe there are too many systems everywhere they go, and they are too busy. They only want to scribble on a piece of paper and zoom out again...All up it is about 13 doctors [come to our RACH]...They all have access, and I even ask them if they would like me to show them how to use the system, as it might be easier for them, and they always reply that they are in a rush. - Manager 82

\section{Difficulty in generating reports and predicting trends}

A physiotherapist assistant expressed her frustration that the reporting and graph generation functions were missing. A report or graph generated as a Microsoft Excel spreadsheet to show trends would be welcomed. 
Managers had to review a large amount of documentation to find information. Two managers suggested a function which could show a trend or a pattern from the change of patient data (e.g. weight) during a certain period of time.

...when you are looking at weight, you can't easily see: oh they have lost half a kilo in a week. Sometimes it's difficult to have to click through a dozen pages to find the information. If some information was all on one chart that would be better. - Manager 326

\section{The lack of a built-in spell-check function}

Seven nursing staff members mentioned that they would like to have a spell-check function in the EHR system. One reason was that spell-check could save nursing staff members time spent proof reading and changing wording. It would also be convenient for care workers who have a lower level of English literacy to enter data correctly.

Then only problem I think is people's spelling...also when you are typing really quickly, the fact it doesn't give you a line when you spelt something wrong like in Word. - Other 578

\section{The additional functions needed}

A manager suggested a form validation function when nursing staff members filled in charts and forms. There were a number of blanks in charts and forms which could be defined as required fields that must be filled before the form could be saved. In addition, some documents could also be defined as required to be created or updated after a certain period of time. If they were not finished in time, the system could notify the nursing staff to do it. This function would be useful for managers to auditing the documentation.

Perhaps if a progress note hasn't been filled in after a certain time, a notification would pop up, or an alarm or something; or something like blood pressure, if somebody's blood pressure is not put in, it will alert us...That would be good rather than me having to manually double check to make sure everything is filled in; or something like the program restricts you from filling in your progress notes until other important tasks such as blood pressure have been recorded. Manager 349

After a system update, a manager found one of the useful functions had disappeared. The information in certain assessment forms used to be linked with the progress notes and she would like to see it reinstated.

I mean before the [System Y] upgrade a lot of the assessments we did were directly linked with the progress notes, and now it's not and I don't like that. - Manager 341 


\subsection{Resistance to using the system}

Some staff attitudes toward reading and entering data in the EHR system were found to be negative. 47 entries recorded from 34 (31\%) nursing staff members reported the problem of resistance to using the EHR system by their colleagues or themselves. The reasons for resistance are analysed in the following sections.

\section{Who was resistant to use the EHR system?}

17 entries from 15 nursing staff members (14\%) mentioned that they thought there was still a small number of nursing staff members at all levels who were reluctant to use the EHR system.

15 nursing staff members (14\%) reported some of the GPs who visited the RACH never used or were reluctant to use the EHR system in the RACH. Two staff members reported a physiotherapist did not record in the system. A manager self-reported that she preferred the old way of documentation in the paper folder and forms. Three reported RNs' difficulty in accepting the new EHR system. In particular it was said that one experienced RN 'will come to work as long as we don't have to use the computer'. Five nursing staff members (5\%) reported that some PCWs were resistant to documenting in the EHR system.

So we have to be careful that we refer to in written notes...They [the doctors] would rather you hand them the written note, and they scribble what they want to do. On computers they have to put in the password, then flick, and do a few procedures before they can start writing their progress notes. Sometimes it’s too hard. - Manager 67

She [the physiotherapist] has good computer skills, she has a laptop of her own but she doesn't particularly want to. She charges us about \$110 an hour. She came for three hours and she said you'd need an extra hour if you wanted her to use a computer. That's why I transfer it [her documentation work] over because obviously I cost them a lot less than she does. - Other 154

\section{Why are some staff members reluctant to use the EHR system?}

36 nursing staff members (33\%) expressed their opinions about why some nursing staff members were reluctant to use the EHR system. The reasons included the age of the nursing staff, a lack of computer skill, a lack of documentation skill and a combination of time limitations as well as staff preference for spending time with the residents. 13 (12\%) nursing staff members reported slow adoption of the EHR system and they attributed the phenomenon to unwillingness to change and time pressure. The age factor was mentioned by 8 nursing staff members (7\%). Low computer literacy or lack of typing skill was mentioned by 10 (9\% of) 
nursing staff members. This occurred at all levels of nursing staff members and outside health care providers. Limited time and preference for providing direct care over documentation were also mentioned by 10 nursing staff members (9\%), who believed that the problem occurred with GPs, a physiotherapist, ENs and PCWs.

The language barrier and lack of documentation skill were also mentioned by some nursing staff members. Many staff members, including cleaners, catering staff and PCWs in RACHs, came from non-Englishspeaking backgrounds. They were more likely to struggle with using the correct language and were sometimes not fully skilled in documentation.

When you have got people in the workforce who have been here for 20 years, they are not as familiar with computers as the younger generation are so it is a little bit of a fear factor...I think that the big risk is that we have half of them using it and half of them not, so there is not that collaboration...The younger staff would have gone 'oh this is fantastic' because for them it is what they do; whereas for the older staff who have never turned a computer on, it is very, very daunting. - Manager 73

The outside health care providers, such as doctors, were the group of people who were most likely to not use the EHR system. The reasons for GPs not using the system included: wanting to use their own electronic or paper-based system instead of recording duplicate information in 2 systems, which showed their concerns about system interoperability because of the data entered in the EHR systems in RACHs being unable to be sent back to their own offices and systems; having concerns about information security; lacking familiarity with computers; forgetting their account name and/or password or being too busy to record data.

\subsection{Increased complexity of information management}

The implementation of EHR systems was expected to improve information management by enabling more information to be processed faster electronically, reducing paper documents as well as improving the quality of health records. However, not all the nursing staff members agreed that such benefits had been fully realised. 50 entries from 34 (31\%) staff members mentioned UCs of the system on the RACHs. The UCs were grouped into 4 categories: different versions of the same document used by different RACHS in the same organisation, problems of data storage, difficulties of managing information on both electronic and paper-based documentation systems and decreased quality of health records. 


\section{Different versions of the same document used by different RACHs in the same organisation}

A manager from Organisation 2 expressed her frustration in auditing health records in System Y. There were multiple RACHs belonging to Organisation 2, however different RACHs were using different versions of the system. The manager felt confused and thought that it was more time consuming for her to go through the same type of documents in the various different versions.

We need to be consistent throughout the region to eliminate different versions of [System Y]...when I'm auditing someone else's progress notes and doing clinical research. I have to think, what version are they using? Are they using the old version, the new version? That's what can be time-consuming on my part. - Manager 129

\section{Problems of data storage}

A few nursing staff members felt frustrated when they encountered problems in data storage. Two managers from Organisation 2 mentioned that they lost data such as care plans and some charts they had entered but which had not been saved by the system. The reasons might be user error caused by nursing staff members who did not save the records or error by EHR System Y itself.

Other complaints were about whether a saved EHR could be changed or not. A manager who used System Y reported that the error she made in documentation could not be deleted when she wanted to. However another PCW who used System X expressed her concern when she saw the record could be modified by other staff members, as she said:

The only thing I am not happy with is how you can go in and edit someone else's work if you want to. You can go into someone's work and edit without them knowing...you shouldn't be able to go into someone else's notes. Like you can't do that on paper but you can on computer. PCW 36

Discussion with the managers suggested that although changes were allowed to be made to the recorded data in EHR System Y, any changes, along with the ID of the person who made the change and the date of the change, were recorded in the system log permanently to comply with legal requirements for resident health records. So the PCW's concern was originated from a lack of understanding about how the system handling changes made to a saved record, suggesting a lack of communication of the information to her. 


\section{Difficulties of managing information in 'mixed' system of paper-based and electronic documentation}

None of the RACHs surveyed made a complete transfer to the digital system from their paper-based documentation practice. Some of the paper documents were kept because nursing staff members thought it was not practical to enter certain types of records on computers. Such documents were still on paper in Organisations 1 and 3. These included (though not in all of the RACHs) the communication book (for example, records of haircuts and fingernail cutting), the nursing diary (for example, records of visitors and appointments), incident forms (accident reports), residents' files (for example, catheter changes), attending doctor's book or other documents that were prepared for use by outside health care providers, medication charts, bowel charts, showering and washing charts, wound charts, pain assessments and dressing charts.

One of the causes of this was the inconvenience of accessing the EHR system because there was a shortage of computers and the staff members were too busy to access the computers at the nurses' station during the care delivery process. Other reasons included lack of functions for the allied health professionals to initiate their assessments or draw diagrams in the system, inefficiency of entering data and system downtime. For these reasons, nursing staff members still could not entirely avoid the paper-based documentation system.

Personal care records are still on paper because nurses have to fill them in on every shift and it just wasn't practical to have 4 nurses at 3 o'clock trying to get on a computer. So we keep on a paper basis. - Manager 176

And we tend to still do our bowel charts on paper. And personal care records such as the fact that staff have showered on that day, we find that if it was on the computer, it would be very slow and haphazard. Plus you have to go into each individual resident to do that, whereas you can have that on one piece of paper for the staff. - Other 204

All the RACHs had paper-based documentation backup systems in case the EHR system went down. In some RACHs, staff recorded on paper when the system was shut down and scanned the paper documents into computers afterwards. In other RACHs, staff just entered 'the system was down on the day' in the EHR system. Staff members were also using printed health records. Printed care plans were put into wards for easy access by nursing staff members or just for RNs to evaluate. Some nursing staff members thought that having 
a paper documentation system and the EHR system at the same time had reduced the administrative efficiency and increased the difficulty of managing information.

One that I find difficult that we do is a nursing care plan - not the formulation of, but when you do the evaluation, and we take a hard copy. But if you do that every 2 months you think 'look at all this paper' which to me is defeating the purpose of having an electronic system. - Manager 178

I suppose eventually when everything's moved over to the computer, and there's no more paper - well I mean there has to be some paper - but when everything's that goes on there... um... yeah. I think it will be a lot less confusing when it's all on one thing. - RN 192

\section{Decreased quality of health records}

There were 20 entries from 19 nursing staff members (17\%) who reported that the quality of health records was not improved or even deteriorated. The complaints focused on the content of health records being inaccurate, incomplete or out-of-date.

The accuracy of the information from the EHR systems was perceived to be somewhat worse by 9 (8\% ) nursing staff members interviewed. This included 3 (10\%) managers, 2 (13\% ) RNs, 2 (4\% ) PCWs and 2 (15\% ) other staff. A manager reported that newly recruited staff using System X could not get their own account to log-on the system so they logged on through a generic account. From the manager's point of view, this removed responsibility for quality documentation because it meant that there was no individual signature. The manager also mentioned that the system was not updated since its initial introduction in 2006 and the lack of technical support from either the vendor or the IS services in the organisation caused this situation. Meanwhile, according to some staff members using System Y, some electronic forms asked for wrong information to be filled in and gave wrong options. This meant that the essential information these staff should have been entering could not be entered in the system.

They [new recruited staff] have to do it through generic login. So in some ways, it removes some of their responsibility...traceable from a quality point of view, that [it's not good because the documents are meant to be signed individually] is not correct. - Manager 64 Except sometimes when you are filling out forms there isn't an option that is appropriate, and if you could scrub out the options and write your own... You know, for wound care or something you might have several different options, none of them was exactly the right one. $-R N 164$ 
Six nursing staff members (5\%) who thought the information in the EHR systems was incomplete, possibly because the scope and content of the electronic form were not designed properly for them to enter rich and complete information in comparison with the flexibility given by the previous paper documents. Also, as mentioned above, at times there were signatures missing in the EHR system because of the inconvenience of accessing the system. In addition, staff members were just too busy to finish all the documents or a few staff members did not treat all types of health records seriously.

Sometimes you don't get time to do your progress notes. Always get your bowels done whether they've had their bowel charts, they are pretty important. But progress notes they don't, depended whether you get time.' - PCW 135

The information in the EHR systems was not always up-to-date. In Organisation 1, 4 staff members reported that they encountered synchronisation problems when using System X. Nursing staff reported that the information they saved in the system disappeared for 2 weeks, and the transfer of information they entered in a notebook to a desktop computer was too time-consuming. Another staff member complained that because of the limited number of computers, she could not access one during her shift. When that happened, she would document one day later so the information was not entered in a timely fashion...

Like it [the EHR system] worked fine every morning, then the last part of the day it [the laptop] didn't connect to the wireless. It saved everything I put on. But then I had to hook it up in [person X]'s office, with the cable, and then we had to wait for it to download everything that I'd typed so I could run off a sheet for every unit as to what happened on doctor's day. - RN 54

\subsection{Concerns about access}

40 entries from 33 nursing staff members (30\%) reported concerns about access to the EHR system. There were 3 reasons for this: an inadequate number of computers on the floor, technical problems and end-user mistakes.

\section{Inadequate number of computers}

14 (13\% ) nursing staff members, including 2 (6\% ) managers, 3 (20\% ) RNs, 5 (11\% ) PCWs and 4 (30\% ) others from all 3 organisations reported that there was an inadequate number of computers on the floor, especially on day and afternoon shifts in high care homes. They reported that the AHPs and RNs had priority to use the computers, so sometimes it could be difficult for a PCW to access the EHR system. The PCWs 
were used to documenting at the end of a shift but because the computers might all be occupied by then, some PCWs tried to document during break time or any other time they could squeeze in for documentation, and this was not always achievable. The nursing staff members would either ask their colleagues to let them use the computers or choose not to document at that time.

We have three [computers] on south wing. I think there are two in the RN's office. There's I think two in the staff room and then there are many on the other side of the wing. I don't know. But there are times when we are running around trying to find a computer. - PCW 224

\section{Technical problems}

Technical problems were either caused by the EHR system itself or third-party products. These problems were usually solved quickly. The other technical problems included inappropriate use of the system and a lack of portability of the devices used to access the system.

Third-party product failures: The technical problems caused by third-party product failures included temporary power outages, lack of internet access and hardware breakdown.

When the EHR system broke down, the nursing staff could only rely on limited information in their paperbased back-up records, which caused frustration with the EHR system.

[Person A] can't do it [the documentation] because the computer has been overhauled. So the hard drive's been replaced ... - RN 56

Inappropriate use of the system: Inappropriate use of the system occurred when a nursing staff member would log on to a vacant computer for a long period of time without using it, and this blocked access by others to the EHR system.

When you do have time and you do find that five-minute window, somebody is already [logged] on the computer...I have to switch it off, and then you have to wait for it to reboot again. And by the time you're ready to start, the buzzers are going again and you've got to go...it's very inconsiderate I think, that somebody hasn't logged off. - PCW 52

Device portability: There were 5 nursing staff members (5\%) who had concerns with the portability of the devices that were used to access the EHR system - computers were simply more cumbersome than a piece of paper. When staff members took notes while in a ward or conference room, paper records were convenient to 
carry. It was difficult to carry a computer for data entry while walking and talking. In addition, a manager reported that she could not access the system when she took a resident to a hospital.

But if you ve got a piece of paper on you, you can be walking and still jotting down really quickly as you go. - PCW 11

If I go with a resident to hospital I can't write the progress notes until I get back, so I had to write it early the next morning. - Manager 101

\subsection{Increased documentation burden}

30 entries from 24 nursing staff members (22\%) reported that it was inconvenient and inefficient to use the EHR system, citing the time-consuming nature and/or inconvenience of log-in, data entry and retrieval. Some nursing staff members complained that the log-in speed was slow.

I think that they [the doctors] do have some complaints, saying the log in process is too long and with that process, they would have already finished their handwriting. - Other 203

The slow speed of the computer and the slow process for nursing staff members to interact with the system were also reasons why it was time-consuming to use the EHR systems.

It is good because the RN uses the one at the desk, and these notebooks are slow. - RN 29 17 nursing staff members (15\%) thought using the EHR system was too time-consuming for data entry. Some charts were perceived to be complicated enough to confuse nursing staff. Some nursing staff members were unhappy with the EHR system providing a different process and poor workflow of documentation in comparison with their previous paper-based system. Six entries from 6 nursing staff members (5\%) stated that it took time and many steps to open up the charts and forms nursing staff members intended to review, causing them to spend more time on finding the relevant pages for data entry. It was reported that some relevant information had to be entered into different pages of the EHR system, which was illogical and inconvenient.

Some particular types of data, such as bowel charts and progress notes, were perceived to be quicker to write down than to enter into computers. This is because accessing a piece of paper was easier than moving between a computer and a ward, and waiting for log-in. To save time, some nursing staff members chose to 
take a piece of paper with them to note the important information right after finishing the task, and then enter the data into the computer at the end of a shift.

I don't think it [the EHR system] is quick because when you are on the job and something happens, it is better to make notes on your piece of paper that you have with you, with the resident's name than to stop what you are doing and then go make progress notes. No, you have to do it at the end of the shift. - PCW 12

I find sometimes the computer doesn't work quickly enough. - Other 183

I'm particularly slow. I usually leave my documentation until the last thing so that if I need a bit of extra time I can stay a bit later. - RN 167

A PCW reported dissatisfaction with search results. A manager reported the difficulties in retrieving all of the charts and assessments for completing the funding instrument ACFI.

You've got to click down to another page and when you've found it, it automatically goes back to creating a new form - it's just a bit cumbersome, it isn't difficult but it's the only thing that is a little bit time-consuming, particularly when I'm doing ACFI assessments and I want to see what charts and assessments have been done and I want to see that they're all in there. Manager 175

\subsection{The reduction in communication}

There were 9 nursing staff members (8\%) who suggested that the introduction of the EHR system did not facilitate communication either internally among staff, or externally with outside health care providers. One manager expressed her worry about staff losing the sense of belonging with the introduction of the EHR system, because of the reduction in face-to-face communication and this was perceived to affect team work negatively.

It was reported that some nursing staff members still relied on verbal communication. In particular, some PCWs preferred to ask RNs for up-to-date information rather than accessing the systems by themselves. Because the RNs were already on computers, asking was quicker than checking on other computers or perhaps this was simply the culture in the RACHs. The low adoption of the EHR systems by the doctors hindered communication between the doctors and nursing staff. In addition, it was reported that some staff did 
not send a resident's health information to the hospital when the person was transferred to hospital because they were not familiar enough with the system to retrieve the relevant information.

However I know of other staff who aren't that familiar with [System X] who don't use it in that way. They wouldn't send that information to hospitals, so that's when we get phone calls 'does so and so normally communicate in this way'. - Other 5

\subsection{Lack of space to place enough computers in the work place}

Nine participants reported that after the implementation of the EHR system, more space was required to place an adequate number of computers. Compared to handwriting on paper-based records, computers required more space in nurses’ stations or offices. With several computers the office could be crowded, a manager stated. She realised that the RACH needed more computers for staff members, and it was a challenge to find more space for these computers.

Although the computers were usually located in nurses’ stations and offices, 8 nursing staff members (7\%) suggested other locations. Apart from the suggestion of evenly distributing the computers in the building, an overwhelming majority suggested placing the computers in quiet areas so they could sit down and concentrate on entering data into the EHR systems, especially for lengthy documentation. This would be conducive to reducing time on documentation. On the other hand, even though more computers were needed, it was suggested that there was actually no room to place them. One manager suggested that computer space needs to be considered in the designing of a new RACH.

So a couple more [computers] in quiet areas would be good. Like when you're doing normal notes or progress notes on the floor, it's not a problem. But when you are doing a long job, it becomes a problem. - PCW 570

\subsection{Increasing difficulties in delivering care services}

Although it was agreed that the EHR systems facilitated documentation, 7 staff members believed that the system did nothing to improve clinical processes and care services, which remained the same before and after the introduction of the EHR system. In fact, 5 nursing staff members (5\%) commented that the EHR system made it more difficult to deliver care services compared with the previous paper-based system. 
The UCs in this category were further classified into 2 sub-categories: no difference in care decision making and potential risks of lacking care follow-up.

\section{No difference in care decision making}

The nursing staff members who thought there was no difference in the quality of care before and after EHR implementation all focused on the impact of the EHR system on care decision making, which was not believed to have been improved. Three entries from 3 nursing staff members (3\%) reported this. One reason was that older nursing staff did not use the system effectively because they were not computer literate. One nursing staff member who reported the issue came from Organisation 1 using System X, the other 2 came from Organisation 3 using System Y. They believed that the system they were using would help them to retrieve previous records but had no direct impact on their care decisions making. They emphasised that it was not the system, but nursing staff members who made the care decisions.

For carers on the floor, I don't think the software itself makes their job any easier or worse. I think it makes documentation easier. For me the clinical process or the caring, documentation whether paper based or electronic, it's just a component of that, the actual care is not different. - Manager 20

No, [System Y] does not help you make decisions as far as your nursing decisions go. That's something that I think we do. I suppose if you are looking at what you've done in the previous week or something, then [System Y] can help but it's only about the documentation that nurses put in there anyway. - RN 206

\section{Potential risks of lacking care follow-up}

The risks related to care follow-up were also reported. The staff could follow up the wrong care services because they were not always accessing real-time information. In Organisation 2, care practice involved staff members putting hardcopy care plans in the wards. A manager from this organisation reported the risk of staff accessing out-of-date hardcopy care plans in the ward even though the electronic care plan had been updated. A physiotherapist expressed her concern that the staff on the next shift or the next day might not be aware of changes that had been made on residents' records.

If I go into the notes and write something in today...if someone comes in tomorrow or the next day, they don't go back to that page. They don't know that I've seen them...I don't see the same 
people all the time, and some people I might only see once a week. And it might be just harder to flick back once a week on a computer screen than it is on a paper. - Other 137

\section{Discussion}

After an extensive reporting of the benefits of EHR systems in RACHs, this study focused on identifying UAC caused by the introduction of these systems in the same organisations. The authors interviewed 110 users of two different EHR systems used in 9 RACHs belonging to 3 aged care organisations in three states/territories in Australia. The transcripts were analysed to elicit content information about UACs. 78\% of nursing staff members had encountered different types and different levels of UACs in all participant RACHs. DeLone and McLean’s Information Systems Success Model provided a conceptual framework for the establishment of a classification system of UACs. The classification system established by Campbell et al. [17] was also referenced. The structure of the article follows the STARE-HI guideline for health informatics evaluation studies [42].

The identified UACs were classified into 8 categories: inability/difficulty in data entry and information retrieval, resistance to using the system, increased complexity of information management, concerns about access, increased documentation burden, the reduction of communication, lack of space to place enough computers in the work place and increasing difficulties in delivering care services.

In the previous study, the authors classified the benefits of the same EHR systems based on the same data set. The purpose of introducing EHR systems in RACHs was to bring benefits such as improvement of documentation quality and efficiency, general information management, communication, quality of aged care services and reduction of documentation burden on nursing staff $[1-9,11]$. To give a balanced view of the impact of the EHR systems on information management and aged care services, a comparison of the number and percent of participants reporting the benefits (refer to [11]) and the UACs is given in Table 2.

Insert Table 2 here.

The results presented in Table 2 suggest that more benefits than UACs were realised by the introduction of the EHR systems in the RACHs. The 6 categories of net benefits mentioned by the nursing staff in the participating RACHs were: increasing the amount of information content that had facilitated nursing staff's 
work, empowering nursing staff, facilitating communication between nursing staff and the residents, improving access to funding, facilitating care quality control and educational benefits.

More nursing staff members praised five categories of benefits than mentioning the counter UACs. 89 staff members saw the most significant benefit as improving convenience and efficiency in documentation. Conversely, 24 participants considered the EHR systems to be inefficient. More staff members praised the improvement in information management than those who complained about its increased complexity (48 vs. 34 staff members). Approximately one third of the participants agreed that the system improved their access to the documentation system (39), thus facilitating communication (33) and care quality improvement (33). On the contrary, relatively few participants complained the system had hindered their access to the documentation system (33) and communication (9), causing difficulties in care service delivery in comparison with the paper-based system (7).

Inability/difficulty in data entry and information retrieval caused by inadequate functionality and poor interface design of the EHR systems (44), user resistance (34) and lack of space to place enough computers in the workplace (9) were perceived to be substantial UACs hindering the realisation of EHR benefits. These, together with other UACs, should be controlled and ideally eliminated for the continued sustainable use of the systems. Otherwise the unsatisfied users may be reluctant or even refuse to use the system to enter the essential clinical records and resort back to paper.

Such EHR avoidance was heard of by the authors after the completion of the study. User resistance to entering essential clinical data may cause missing health records, which is a direct risk to safety of the residents many suffering from multiple complications [43] or memory loss [44]. It has the potential to cause medical errors in the care for these vulnerable and frail people [24-27]. Thus it is a serious concern that needs to be appropriately managed.

The number and types of UACs varied in different RACHs, possibly caused by the differences in many environmental and system factors. The initial conditions may include the structure, culture, staffing, job allocation and normalised work practices in the RACH, in addition to its architectural design, layout and physical infrastructure. The system factors include the differences in functionality between the two EHR 
systems and between an EHR system and the previous paper records, the compatibility of EHR systems with nursing staff members' workflow and information needs. Another factor is the way the system was introduced which may include implementation strategies, training and support mechanisms to orientate and improve end users' knowledge and capacity in using computer, the EHR system and nursing documentation. An in-depth discussion of the causal factors of UACs is given in the following sections.

\subsection{The UACs caused by initial conditions and the mitigation strategies to deal with them}

Some UACs were caused by the initial conditions of the RACHs. For example, internal communication was not facilitated by the EHR system because the nursing staff members prefer verbal communication to pass information, which is common in health and aged care [45, 46]. Indeed, this culture is deeply rooted in healthcare and the simple reason for its prevalence is convenience and effectiveness of communication and collaboration. We should not over-estimate the role of IT in healthcare [34], but we need to develop communication technology in order to support information exchange [47].

There were also concerns about losing human contact [48] and teamwork spirit if care staff members spent too much time on the computer. Campbell et al. [17] emphasise the danger of the UAC of not-on-time or even no care follow-up when changing communication practice from face-to-face to using the computer. BeuscartZéphir et al. [49] also identified the problem of reduced doctor-nurse communication when CPOE systems were introduced in three French hospitals. It is recommended that the RACHs monitor the team work of care staff and foster a culture of continuous collaboration.

Decreased accuracy and completeness of information in EHR systems [33] was identified in this study. This presents a risk of decreasing the quality of care service delivery and increasing medication error [24], in addition to the increased difficulty of information management for RNs and nursing managers. It can be caused by the inadequate functionality of the system [29] which did not provide a complete platform for nursing staff members to record the essential data required for nursing care. It should also be noted that the quality of information is also directly linked to the capability of nursing staff in documenting care [50]. Some sub-optimal or fault records in the EHR systems were believed to be entered through human error often by less capable staff. 
To our knowledge, the vendors were continuously upgrading the EHR systems to improve the functionality and interface of the systems. When any deficiencies in the system were reported, the vendors were making effort to addressing the deficiencies of the EHR systems. There might be two reasons for the reported incidence of good functions disappearing with upgrades: (1) software deficiency, which would be fixed by the next upgrade; (2) human factor of lacking familiarity with the new interface, which could be solved by a refresher course offered to the users after each software upgrade. The capability of nursing staff in documenting care has also been an ongoing challenge for the residential aged care providers who suffer from workforce shortage, whether using paper or electronic record systems. The solutions for this have varied according to organisational values, size, priorities and resources.

DeLone and McLean suggest that UACs can be caused by user resistance [37]. The three major factors which cause resistance are the perceived nature of professional work, staff attitudes towards information management and time pressure. The GPs were the major professional group who were reluctant to use the EHR systems in RACHs [30] because of their pressure for the divery of direct medical care within a limited time frame, also they did not see the benefit of data entry for themselves when they could not access the data in their offices. Some nursing staff members were also reluctant to use or even avoided using the EHR system because they saw delivering quality nursing care to the residents as their main duty and resented spending time on administrative work [8]. 'Too busy providing care to the many residents' and 'simply no time to document' [51] were the main reason. Other factors causing resistance were poor knowledge about the significance of information management for aged care service delivery, ownership of information, a lack of basic computer and documentation skills and resistance to change.

\subsection{The UACs caused by the EHR systems}

Some UACs were the direct effects of the nature of the EHR systems. For example, some nursing staff members thought that the EHR did nothing to improve their decision-making abilities, as suggested by our observational study [45]. This reflects the fact that although the EHR systems under investigation were successful in automating the paper-based forms, charts and documents, they were yet to build smart decisionsupport functions to facilitate the nursing staff to solve clinical problems better and faster. 
The less favourable quality of the EHR systems was believed to be one of the original sources of UACs [37]. The EHR systems can be inconvenient and inefficient to use [15, 17, 19, 20, 26, 33] for some types of data entry and retrieval, such as continence data collection [32]. Consistent with our finding from the observational study, some staff felt that more time was spent on log-in, data entry and retrieval using the EHR system than doing it on paper [12]. Such inconvenience and inefficiency led to the UACs of hindering aged care service delivery and paper persistence in RACHs [17, 52], both of which were found to be common in the participating RACHs. Fichman et al. [53] also suggest that the continued use of paper records is driven by its convenience and flexibility. This suggests that the EHR systems were not as convenient or as flexible as paper for nurses as they move about the wards. The vendors may easily resolve the inconvenience by re-designing the functions.

In addition, using a mixed system of both electronic and paper documentation had reduced the administrative efficiency and increased the complexity of information management, thus causing RNs to spend more time on documentation, reducing time spent caring for the residents [29, 54]. Berg argues that paper-based documentation provides an active and efficient way to collect and aggregate data, and the flexibility of shuffling through the records and getting an overview [34]. These functions are often under-estimated. It may take a long time and substantial, radical technology innovation for any electronic system to catch up with these advantages of paper-based systems.

The external communication was not fully facilitated by the EHR system simply because of GPs not using it. This UAC lends support to the importance of interoperability and data sharing across healthcare organisations for realising the optimal benefits of EHR, an important goal of the current Australian government initiative of Person-controlled Electronic Health Records (PCEHR).

An easy-to-use EHR system with appropriate functions is fundamental for realising its benefits [8]. In this study, many nursing staff members complained about system performance due to bugs, unfriendly user interface design [17, 20, 25] and lack of functions [33] either specific for an EHR system, such as a lack of certain types of forms and charts, or common functions the staff had seen or used in generic software, such as spell check [29] and diagram drawing. Mismatches between information flow (entering and retrieving data) in 
the EHR systems and nursing staff's workflow and information needs were also common [17-19, 26, 54-57]. This shows that it is important to understand nursing staff members' information needs and work practice and design the forms to meet these needs following the optimal process. Local customisation of system function and knowledge presentation was suggested to be highly useful for fitting the system with specific workflow and information needs to improve the efficiency of nursing documentation [57-60]. Poor interface design has long been recognised as a significant barrier to the effective function of clinical information systems in health care [61]. Re-engineering of the human-computer interface is a solution to some of these problems [49].

The function of pop-up windows to highlight the latest information that a user needs to have when logging on to the EHR system was greatly appreciated by the nursing staff who used it. This function was seen as facilitating communication of key organisational messages to nursing staff members on the floor, who often had no opportunity to have contact with the management team in the organisation.

\subsection{The UACs caused by the way the EHR systems were introduced into the workplace and used by nursing staff}

Introducing EHR systems includes an implementation strategy, training and support mechanisms used to help nursing staff members to adopt the EHR system and the set up of information management infrastructure. All had significant impact on how the systems were used by the nursing staff. Different versions of electronic forms, charts and care plans were used by different RACHs in one organisation, causing confusion to clinical nurse consultants who were responsible for auditing records in these RACHs. This has increased the complexity of information management in the organisation. It is recommended that this operational complexity can be eliminated if the RACHs in the organisation take a consensus approach to the design of the component forms and the interface of each form in the EHR systems.

Jiang et al. [62] suggest that the strategies and practices for promoting user adoption of an IS should differ according to the type of system introduced or the organisation where the system is introduced. Previous researchers have provided several useful suggestions for decision makers to consider in developing or selecting appropriate strategies to promote EHR systems in the health and aged care sectors. In terms of implementation strategy, strong policy support, engagement and push from top leadership will encourage 
nursing staff members to commit to and engage with the system [63]. A flexible change management strategy with an actionable vision outlining realistic goals was suggested for EHR implementation [58].

Shortage of computers [48] was found to be an UAC in this study, including the reported challenges of finding a suitable location for them. It caused difficulties in accessing the EHR system. Alexander et al. [54] suggest the site preparation should begin during the design phase of a new RACH by assessing RACHs for any special accommodation requirements (equipment space, network wiring and end-user space requirements). The number of computers in an RACH varies according to the number of nursing staff and their documentation habits. A quiet place where nursing staff can concentrate on documentation is favored by many for optimal electronic documentation. These problems can be identified by the IT support team in the organisation through the establishment of a convenient communication channel between the end-users and the IT support team. The commitment by top management to ongoing resourcing of continuous system maintenance and upgrade is necessary for the resolving of these challenges.

Portable devices were considered to have the potential to increase the accessibility to the EHR systems [39], however they can generate new problems. Internal communication may be hindered because the wireless synchronisation process transferring information from a notebook to a desktop computer is slow [54]. Long time technology failure may directly lead to EHR avoidance because nursing staff members were conscious about the UACs of overdependence on the technology $[17,55]$. Thus a stable and well-performing wireless environment and the presence of technical support staff in an RACH were both suggested, although the cost implication for the second recommendation may need to be justified. Hopefully, the introduction of the national broadband network (NBN) by the Australian government and the fast advancement of wireless network technology will lead to resolving these network infrastructure challenges for EHR systems in the near future.

Consistent with Campbell et al. [17], the challenge for nursing staff to adapt to the use of the EHR systems was commonly found in our study. It was partly caused by their unfamiliarity with, or fear of, computers [5, 64]. This problem suggests, in part, a lack of training. An adequate training program is widely accepted as a facilitator for the adoption of any new technology, including EHRs [48, 54, 64]. It should be provided to 
system users during the implementation phase and needs to continue after system implementation [48]. To improve training outcomes, the training program should be properly designed for users to acquire the necessary skills and allow nursing staff members with low computer literacy to learn to use the system at their own pace [63].

\subsection{Limitations}

One limitation of this reporting is a complete dependency on participants' subjective perceptions, lack of objective observational data to support the classification of UACs due to space limit. However, we have also conducted extensive observational study [32, 33] in one of the participant RACH and thus were confident with the accordance of this reporting with the observational results. In addition, using the D\&M IS Success Model may present challenges for a researcher to approach the data neutrally. The authors made every effort to avoid overemphasis on fitting the data to the constructs in the model by using the principles of grounded theory to classify and compare the context. This is believed to have increased the reliability and validity of the findings. As the findings are drawn from interview data collected from nursing staff in RACHs, caution is required in generalising it.

\section{Conclusion}

Although the benefits of the EHR systems were obvious[11], introducing EHR systems in RACHs can also cause the unintended adverse consequences of EHR avoidance, difficulty in access, increased complexity in information management, increased documentation burden, reduction of communication and the risks of lacking care follow-up. These could pose negative effects on aged care services. These documented UACs were caused by the initial conditions, the nature of the EHR system and the way the EHR system was introduced in the workplace and used by nursing staff.

Further research should focus on investigating how the UACs can be controlled or eliminated by understanding more about nursing staff's workflow as well as the information flow in RACHs for the purpose of improving the design of the EHR system to fit with nursing staff's work process and information needs. This requires a constant software update in response to end users' feedback. Implementation strategies should 
be improved to promote user engagement, acceptance and usage of the system to optimise the value of the EHR systems.

\section{Acknowledgements}

The authors acknowledge the contribution of the management and nursing staff members in the aged care organisations who participated in the study. The participating aged care organisations are RSL Care, Uniting Care Ageing South Eastern Region and Warrigal Care. The authors are grateful for Dr Madeleine Cincotta’s contribution as copy editor. The research was funded by the Industry Linkage Grant LP 0882430 of the Australian Research Council (ARC) and five aged care organisations: Aged Care and Community Services Australia, Illawarra Retirement Trust, RSL Care, UnitingCare Ageing South Eastern Region, NSW.ACT and Warrigal Care. The views, findings and conclusions are those of the authors and do not necessarily represent those of the funding body or those of the organisations the authors are affiliated with.

\section{Research Highlights}

\section{What was known before the study?}

- $\quad$ Unintended adverse consequences (UAC) are inevitable in the introduction of HIT.

- UACs have been reported in HIT introduction in hospital and primary care settings.

- Knowledge of UACs of EHR in nursing homes is vital for effectively managing them.

\section{What this study has added to the body of knowledge?}

- A classification system of UAC of introducing EHR in Australian nursing homes.

- Initial conditions, nature of and the way the EHR systems was introduced and used caused UAC.

- The suggestions for improving the design and management of EHR to reduce UAC.

\section{Summary points}

\section{What was known before the study?}

- Good quality aged care EHR systems bring in substantial benefits to all stakeholders involved in aged care services; however unintended adverse consequences (UAC) are inevitable with EHR introduction. 
- The literature has identified a number of UAC of introducing health information technology (HIT) in hospital and primary care settings. These include the negative impact of the system on workflow, workload, cost, user emotion, communication, medical errors and others.

- The knowledge of UACs of EHR systems in RACHs is vital for managing them optimally.

\section{What this study has added to the body of knowledge?}

- Although the benefits of the EHR systems were obvious, introducing EHR systems in RACHs can also cause 8 types of negative consequences: EHR avoidance, difficulty in access, increased complexity in information management, increased documentation burden, reduction of communication and the risks of lacking care follow-up, which pay posing threat to resident safety.

- The UACs documented in this study were caused by the initial conditions, the nature of the EHR system, and the way the EHR system was introduced in the workplace and used by nursing staff.

- The UACs may be mitigated if the EHR systems are designed to fit with nursing staff members' workflow and meeting their information needs, and the appropriate training and support mechanisms are in place to promote user confidence with EHR system and nursing documentation in general.

- The proper usage of a well-designed EHR system is essential for optimising the value of the EHR for aged care services.

\section{References}

1. C. Oroviogoicoechea, B. Elliott, R. Watson, Review: evaluating information systems in nursing, J. Clin. Nurs. 17 (5) (2008) 567-575.

2. A. Martin, C. Hinds, M. Felix, Documentation practices of nurses in long-term care, J. Clin. Nurs. 8 (4) (1999) 345-352.

3. R. Daskein, W. Moyle, D. Creedy, Aged-care nurses' knowledge of nursing documentation: an Australian perspective, J. Clin. Nurs. 18 (14) (2009) 2087-2095. 
4. P. Yu, D. Hailey, H.C. Li, Caregivers' acceptance of electronic documentation in nursing homes, J. Telemed. Telecare 14 (5) (2008) 261-265.

5. P. Yu, H. Li, M.-P. Gagnon, Health IT acceptance factors in long-term care facilities: A cross-sectional survey, Int. J. Med. Inform. 78 (4) (2009) 219-229.

6. A. Cheevakasemsook, Y. Chapman, K. Francis, C. Davies, The study of nursing documentation complexities, Int. J. Nurs. Pract.12 (6) (2006) 366-374.

7. E.N. Munyisia, P. Yu, D. Hailey, How nursing staff spend their time on activities in a nursing home: an observational study, J. Adv. Nurs. 67 (9) (2011) 1908-1917.

8. S.Y.-S. Jeong M. McMillan, Documentation leads to reform: reality or myth, Geriaction 21 (4) (2003) 22-25.

9. W. Dorda, G. Duftschmid, L. Gerhold, W. Gall, J. Gambal, Introducing the electronic health record in austria, Stud. Health. Technol. Inform. 116 (2005) 119-124.

10. G.O. Otieno, T. Hinako, A. Motohiro, K. Daisuke, N. Keiko, Measuring effectiveness of electronic medical records systems: Towards building a composite index for benchmarking hospitals, Int. J. Med. Inform. 77 (10) (2008) 657-669.

11. Y. Zhang, P. Yu, J. Shen, The benefits of introducing electronic health records in residential aged care facilities: A multiple case study, Int. J. Med. Inform. 81 (10) (2012) 690-704.

12. B. Middleton, W.E. Hammond, P.F. Brennan, G.F. Cooper, Accelerating U.S. EHR adoption: How to get there from here. Recommendations based on the 2004 ACMI retreat, J. Am. Med. Inf. Assoc. 12 (1) (2005) 13-19.

13. A.K. Jha, D. Doolan, D. Grandt, T. Scott, D.W. Bates, The use of health information technology in seven nations, Int. J. Med. Inform. 77 (12) (2008) 848-854.

14. D. Gans, J. Kralewski, T. Hammons, B. Dowd, Medical groups' adoption of electronic health records and information systems, Health Aff. 32 (5) (2013) 1323-1333. 
15. E.N. Munyisia, P. Yu, D. Hailey, Does the introduction of an electronic nursing documentation system in a nursing home reduce time on documentation for the nursing staff? Int. J. Med. Inform. 80 (11) (2011) 782-792.

16. N. Menachemi R. Brooks, Reviewing the benefits and costs of electronic health records and associated patient safety technologies, J. Med. Syst. 30 (3) (2006) 159-168.

17. E.M. Campbell, D.F. Sittig, J.S. Ash, K.P. Guappone, R.H. Dykstra, Types of unintended consequences related to computerized provider order entry, J. Am. Med. Inf. Assoc. 13 (5) (2006) 547-556.

18. J.S. Ash, D.F. Sittig, R.H. Dykstra, K. Guappone, J.D. Carpenter, V. Seshadri, Categorizing the unintended sociotechnical consequences of computerized provider order entry, Int. J. Med. Inform. 76, Supplement 1 (0) (2007) S21-S27.

19. J.S. Ash, D.F. Sittig, E.G. Poon, K. Guappone, E. Campbell, R.H. Dykstra, The extent and importance of unintended consequences related to computerized provider order entry, J. Am. Med. Inf. Assoc.14 (4) (2007) 415-423.

20. J.S. Ash, M. Berg, E. Coiera, Some unintended consequences of information technology in health care: The nature of patient care information system-related errors, J. Am. Med. Inf. Assoc. 11 (2) (2004) 104112.

21. M.I. Harrison, R. Koppel, S. Bar-Lev, Unintended consequences of information technologies in health care_-an interactive sociotechnical analysis, J. Am. Med. Inf. Assoc.14 (5) (2007) 542-549.

22. J.S. Ash, D.F. Sittig, R. Dykstra, E. Campbell, K. Guappone, The unintended consequences of computerized provider order entry: Findings from a mixed methods exploration, Int. J. Med. Inform. 78, Supplement 1 (2009) S69-S76.

23. D.F. Sittig, J.S. Ash, K.P. Guappone, E.M. Campbell, R.H. Dykstra, Assessing the anticipated consequences of computer-based provider order entry at three community hospitals using an openended, semi-structured survey instrument, Int. J. Med. Inform. 77 (7) (2008) 440-447. 
24. R. Koppel, J.P. Metlay, A.Cohen, B. Abaluck, Role of computerized physician order entry systems in facilitating medication errors, JAMA. 293 (10) (2005) 1197-1203.

25. A.A. Vogelsmeier, J.R.B. Halbesleben, J.R. Scott-Cawiezell, Technology implementation and workarounds in the nursing home, J. Am. Med. Inf. Assoc. 15 (1) (2008) 114-119.

26. R. Koppel, T. Wetterneck, J.L. Telles, B.-T. Karsh, Workarounds to barcode medication administration systems: Their occurrences, causes, and threats to patient safety, J. Am. Med. Inf. Assoc. 15 (4) (2008) 408-423.

27. J.T. Scott, T.G. Rundall, T.M. Vogt, J. Hsu, Kaiser Permanente's experience of implementing an electronic medical record: a qualitative study, BMJ 331 (7528) (2005) 1313-1316.

28. J.A. Linder, J. Ma, D.W. Bates, B. Middleton, R.S. Stafford, Electronic health record use and the quality of ambulatory care in the United States, Arch. Intern. Med. 167 (13) (2007) 1400-1405.

29. K. Cresswell, A. Worth, A. Sheikh, Integration of a nationally procured electronic health record system into user work practices, BMC Med. Inform. Decis. Mak. 12 (1) (2012) 15.

30. W.O. Hackl, A. Hoerbst, E. Ammenwerth, "Why the Hell Do We Need Electronic Health Records?" EHR acceptance among physicians in private practice in Austria: A qualitative study, Methods Inf. Med. 50 (1) (2011) 53-61.

31. P. Burns, D.A. Perkins, K. Larsen, A. Dalley, The introduction of electronic medication charts and prescribing in aged care facilities: An evaluation, Australas. J. Ageing. 26 (3) (2007) 131-134.

32. E.N. Munyisia, P. Yu, D. Hailey, The impact of an electronic nursing documentation system on efficiency of documentation by caregivers in a residential aged care facility, J. Clin. Nurs. 67 (9) (2012). 1908-1917.

33. P.S. Sockolow, K.H. Bowles, H.P. Lehmann, P.A. Abbott, J.P. Weiner, Community-based, interdisciplinary geriatric care team satisfaction with an electronic health record: A multimethod study, CIN. 30 (6) (2012) 300-311. 
34. M. Berg, Patient care information systems and health care work: a sociotechnical approach, Int. J. Med. Inform. 55 (2) (1999) 87-101.

35. E. Munyisia, P. Yu, D. Hailey, Does the introduction of an electronic nursing documentation system in a nursing home reduce time on documentation for the nursing staff? Int. J. Med. Inform. 80 (2011) 782792.

36. E.N. Munyisia, P. Yu, D. Hailey, The impact of an electronic nursing documentation system on efficiency of documentation by caregivers in a residential aged care facility, J. Clin. Nurs. 21 (2012) $2940-2948$.

37. W.H. Delone E.R. McLean, The DeLone and McLean model of information systems success: A ten-year update, J. Manage. Inf. Syst. 19 (4) (2003) 9-30.

38. W.H. DeLone E.R. McLean, Information Systems Success: The quest for the dependent variable, Inf. Syst. Res. 3 (1) (1992) 60-95.

39. W.-Y. Jen C.-C. Chao, Measuring mobile patient safety information system success: An empirical study, Int. J. Med. Inform. 77 (10) (2008) 689-697.

40. B.G. Glaser A.L. Strauss, (Eds.), The Discovery of grounded theory: strategies for qualitative research, Aldine-Atherton, Chicago, 1967.

41. B. Martin, (Eds.), Who cares for older Australians? A picture of the residential and community based aged care workforce, 2007, Commonwealth of Australia, Barton, A.C.T., 2008.

42. J. Talmon, E. Ammenwerth, J. Brender, N. de Keizer, P. Nykanen, M. Rigby, STARE-HI - Statement on reporting of evaluation studies in Health Informatics, Int. J. Med. Inform. 78 (1) (2009) 1-9.

43. AIHW, Australia's health 2010. Australia's health no. 12. Cat. no. AUS 122. AIHW, Canberra, 2010.

44. Access Economics, Caring places: planning for aged care and dementia 2010-2050. Access Economics Pty Limited., 2010. 
45. E.N. Munyisia, P. Yu, D. Hailey, The changes in caregivers' perceptions about the quality of information and benefits of nursing documentation associated with the introduction of an electronic documentation system in a nursing home, Int. J. Med. Inform. 80 (2) (2011) 116-126.

46. E. Coiera, When conversation is better than computation, J. Am. Med. Inf. Assoc. 7 (3) (2000) 277-286.

47. E. Coiera V. Tombs, Communication behaviours in a hospital setting: an observational study, BMJ 316 (1998).

48. P.-K. Loh, L. Flicker, B. Horner, Attitudes toward information and communication technology (ICT) in residential aged care in Western Australia, J. Am. Med. Dir. Assoc. 10 (6) (2009) 408-413.

49. M.C. Beuscart-Zéphir, S. Pelayo, F. Anceaux, J.-J. Meaux, M. Degroisse, P. Degoulet, Impact of CPOE on doctor-nurse cooperation for the medication ordering and administration process, Int. J. Med. Inform. 74 (7-8) (2005) 629-641.

50. N. Wang, P. Yu, D. Hailey, Description and comparison of quality of electronic versus paper-based resident admission forms in Australian aged care facilities, Int. J. Med. Inform. 82(5) (2013):313-24.

51. S.-Y. Qian, P. Yu, Z.-Y. Zhang, D. Hailey, P. Davy, M. Nelson, The work pattern of personal care workers in two Australian nursing homes: a time-motion study, BMC Health Serv. Res. 12 (1) (2012) 305.

52. J.J. Saleem, A.L. Russ, A. Neddo, P.T. Blades, B.N. Doebbeling, B.H. Foresman, Paper persistence, workarounds, and communication breakdowns in computerized consultation management, Int. J. Med. Inform. 80 (7) (2011) 466-479.

53. R. Fichman, R. Kohli, R. Krishnan, The role of information systems in healthcare: Current research and future trends, Inf. Syst. Res. 22 (3) (2011) 419-428.

54. G.L. Alexander, M. Rantz, M. Flesner, M. Diekemper, C. Siem, Clinical information systems in nursing homes: An evaluation of initial implementation strategies, CIN. 25 (4) (2007) 189-197 
55. B. Kaplan K.D. Harris-Salamone, Health IT success and failure: Recommendations from literature and an AMIA workshop, J. Am. Med. Inf. Assoc. 16 (3) (2009) 291-299.

56. K.M. Unertl, M.B. Weinger, K.B. Johnson, N.M. Lorenzi, Describing and modeling workflow and information flow in chronic disease care, J. Am. Med. Inf. Assoc. 16 (6) (2009) 826-836.

57. J. Lammintakanen, K. Saranto, T. Kivinen, Use of electronic information systems in nursing management, Int. J. Med. Inform. 79 (5) (2010) 324-331.

58. N. Lorenzi, A. Kouroubali, D. Detmer, M. Bloomrosen, How to successfully select and implement electronic health records (EHR) in small ambulatory practice settings, BMC Med. Inform. Decis. Mak. 9 (1) (2009) 15.

59. M. Berg, Implementing information systems in health care organizations: myths and challenges, Int. J. Med. Inform. 64 (2-3) (2001) 143-156.

60. E. Goorman M. Berg, Modelling nursing activities: electronic patient records and their discontents, Nursing Inquiry 7 (1) (2000) 3-9.

61. M.C. Beuscart-Zéphir, F. Anceaux, V. Crinquette, J.M. Renard, Integrating users’ activity modeling in the design and assessment of hospital electronic patient records: the example of anesthesia, Int. J. Med. Inform. 64 (2-3) (2001) 157-171.

62. J.J. Jiang, W.A. Muhanna, G. Klein, User resistance and strategies for promoting acceptance across system types, Inf. Manage. 37 (1) (2000) 25-36.

63. M. Masso G. McCarthy, Literature review to identify factors that support implementation of evidencebased practice in residential aged care, Int. J. Evid. Based Healthc. 7 (2) (2009) 145-156.

64. B. Cherry, M. Carter, D. Owen, C. Lockhart, Factors affecting electronic health record adoption in longterm care facilities, J. Qual. Assur. 30 (2) (2008) 37-47. 
Table 1 - The number and percentage of each position of staff members mentioning the UCs

\begin{tabular}{|c|c|c|c|c|}
\hline Unintended adverse consequences & $\begin{array}{l}\text { Position of } \\
\text { staff }\end{array}$ & $\begin{array}{r}\text { Number of } \\
\text { participants }\end{array}$ & $\begin{array}{r}\text { \% of each } \\
\text { position }\end{array}$ & $\begin{array}{r}\% \text { of total } \\
\text { participants }\end{array}$ \\
\hline \multirow{6}{*}{$\begin{array}{l}\text { Inability/difficulty of data entry and } \\
\text { information retrieval due to inadequate } \\
\text { functionality and poor interface design of the } \\
\text { EHR systems }\end{array}$} & Manager & 18 & $58 \%$ & $16 \%$ \\
\hline & $\mathrm{RN}$ & 6 & $40 \%$ & $5 \%$ \\
\hline & EEN & 1 & $17 \%$ & $1 \%$ \\
\hline & PCW & 12 & $27 \%$ & $11 \%$ \\
\hline & Other & 7 & $54 \%$ & $6 \%$ \\
\hline & Total & 44 & & $40 \%$ \\
\hline \multirow[t]{6}{*}{ Resistance to using the system } & Manager & 20 & $65 \%$ & $18 \%$ \\
\hline & $\mathrm{RN}$ & 4 & $27 \%$ & $4 \%$ \\
\hline & EEN & 1 & $17 \%$ & $1 \%$ \\
\hline & PCW & 4 & $9 \%$ & $4 \%$ \\
\hline & other & 5 & $38 \%$ & $5 \%$ \\
\hline & Total & 34 & & $31 \%$ \\
\hline \multirow{6}{*}{$\begin{array}{l}\text { Increased complexity of information } \\
\text { management }\end{array}$} & Manager & 11 & $35 \%$ & $10 \%$ \\
\hline & $\mathrm{RN}$ & 7 & $47 \%$ & $6 \%$ \\
\hline & EEN & 2 & $33 \%$ & $2 \%$ \\
\hline & PCW & 10 & $22 \%$ & $9 \%$ \\
\hline & other & 4 & $31 \%$ & $4 \%$ \\
\hline & Total & 34 & & $31 \%$ \\
\hline \multirow[t]{6}{*}{ Concerns about access } & Manager & 10 & $32 \%$ & $9 \%$ \\
\hline & $\mathrm{RN}$ & 6 & $40 \%$ & $5 \%$ \\
\hline & EEN & 2 & $33 \%$ & $2 \%$ \\
\hline & PCW & 10 & $22 \%$ & $9 \%$ \\
\hline & other & 5 & $38 \%$ & $5 \%$ \\
\hline & Total & 33 & & $30 \%$ \\
\hline \multirow[t]{6}{*}{ Increased documentation burden } & Manager & 7 & $23 \%$ & $6 \%$ \\
\hline & $\mathrm{RN}$ & 4 & $27 \%$ & $4 \%$ \\
\hline & EEN & 1 & $17 \%$ & $1 \%$ \\
\hline & PCW & 6 & $13 \%$ & $5 \%$ \\
\hline & other & 6 & $46 \%$ & $5 \%$ \\
\hline & Total & 24 & & $22 \%$ \\
\hline \multirow[t]{4}{*}{ Reduction of communication } & Manager & 3 & $10 \%$ & $3 \%$ \\
\hline & $\mathrm{RN}$ & 3 & $20 \%$ & $3 \%$ \\
\hline & PCW & 3 & $7 \%$ & $3 \%$ \\
\hline & Total & 9 & & $8 \%$ \\
\hline \multirow{5}{*}{$\begin{array}{l}\text { Lack of space to accommodate adequate } \\
\text { number of computers }\end{array}$} & Manager & 2 & $6 \%$ & $2 \%$ \\
\hline & $\mathrm{RN}$ & 1 & $7 \%$ & $1 \%$ \\
\hline & PCW & 4 & $9 \%$ & $4 \%$ \\
\hline & Other & 2 & $15 \%$ & $2 \%$ \\
\hline & Total & 9 & & $8 \%$ \\
\hline \multirow{4}{*}{$\begin{array}{l}\text { Increasing difficulties in delivering care } \\
\text { services }\end{array}$} & Manager & 3 & $10 \%$ & $3 \%$ \\
\hline & $\mathrm{RN}$ & 3 & $20 \%$ & $3 \%$ \\
\hline & other & 1 & $8 \%$ & $1 \%$ \\
\hline & Total & 7 & & $6 \%$ \\
\hline \multirow[t]{6}{*}{ Unintended adverse consequences in total } & Manager & 28 & $90 \%$ & $25 \%$ \\
\hline & $\mathrm{RN}$ & 12 & $80 \%$ & $11 \%$ \\
\hline & EEN & 5 & $83 \%$ & $5 \%$ \\
\hline & PCW & 31 & $69 \%$ & $28 \%$ \\
\hline & Other & 10 & $77 \%$ & $9 \%$ \\
\hline & Total & 86 & & $78 \%$ \\
\hline
\end{tabular}


Table 2 - The number and percentage of participants mentioning the benefits and the UACs of the EHR systems

\begin{tabular}{|c|c|c|c|c|c|}
\hline Benefits & $\begin{array}{l}\text { Number of } \\
\text { participants }\end{array}$ & $\begin{array}{l}\% \text { of } \\
\text { participants }\end{array}$ & Unintended Adverse Consequences & $\begin{array}{l}\text { Number of } \\
\text { participants }\end{array}$ & $\begin{array}{l}\% \text { of } \\
\text { participants }\end{array}$ \\
\hline N/A & & & $\begin{array}{l}\text { Inadequate functionality and poor } \\
\text { interface design of the EHR systems }\end{array}$ & 44 & $40 \%$ \\
\hline $\begin{array}{l}\text { Convenience and efficiency in data } \\
\text { entry, distribution, storage and retrieval }\end{array}$ & 89 & $81 \%$ & Increased documentation burden & 24 & $22 \%$ \\
\hline $\begin{array}{l}\text { Improved quality of nursing } \\
\text { documentation }\end{array}$ & 48 & $44 \%$ & $\begin{array}{l}\text { Increased complexity of information } \\
\text { management }\end{array}$ & 34 & $31 \%$ \\
\hline $\begin{array}{l}\text { More information to better understand } \\
\text { the residents and the care services, to } \\
\text { support peer learning and to facilitate } \\
\text { performance appraisal for managers }\end{array}$ & 41 & $37 \%$ & N/A & & \\
\hline Ease of access to the EHR systems & 39 & $35 \%$ & Concerns about access & 33 & $30 \%$ \\
\hline Improving the communication system & 33 & $30 \%$ & The reduction of communication & 9 & $8 \%$ \\
\hline The quality of care & 33 & $30 \%$ & $\begin{array}{l}\text { Increasing difficulties in delivering } \\
\text { care services }\end{array}$ & 7 & $6 \%$ \\
\hline $\begin{array}{l}\text { Staff being motivated to enter data into } \\
\text { the EHR systems }\end{array}$ & 18 & $16 \%$ & Resistance to using the system & 34 & $31 \%$ \\
\hline Empowering nursing staff & 7 & $6 \%$ & N/A & & \\
\hline Improving access to funding & 7 & $6 \%$ & N/A & & \\
\hline Better work environment & 6 & $5 \%$ & $\begin{array}{l}\text { Lack of space to place enough } \\
\text { computers in the work place }\end{array}$ & 9 & $8 \%$ \\
\hline Facilitating care quality control & 2 & $2 \%$ & $\mathrm{~N} / \mathrm{A}$ & & \\
\hline $\begin{array}{l}\text { Communication between nursing staff } \\
\text { and residents }\end{array}$ & 1 & $1 \%$ & $\mathrm{~N} / \mathrm{A}$ & & \\
\hline Educational Benefits & 1 & $1 \%$ & N/A & & \\
\hline
\end{tabular}

